
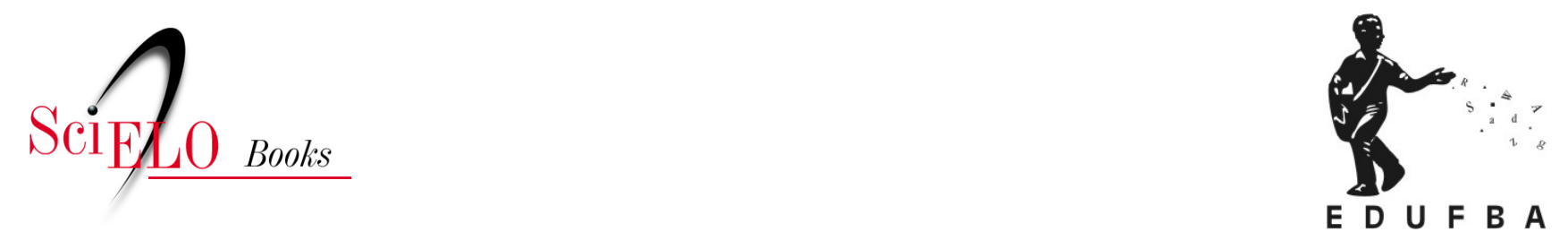

\title{
Flickr e o rizoma da fotografia em rede
}

\author{
Jane C. S. Maciel
}

\section{SciELO Books / SciELO Livros / SciELO Libros}

MACIEL, J.C.S. Flickr e o rizoma da fotografia em rede. In: RIBEIRO, J.C., FALCÃO, T., and SILVA, T. orgs. Midias sociais: saberes e representações [online]. Salvador: EDUFBA, 2012, pp. 4964. ISBN 978-85-232-1734-1. Availablefrom: doi: 10.7476/9788523217341.004. Also available in ePUB from: http://books.scielo.org/id/hcmrr/epub/ribeiro-9788523217341.epub

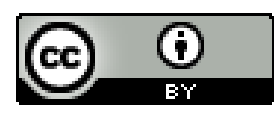

All the contents of this work, except where otherwise noted, is licensed under a Creative Commons Attribution 4.0 International license.

Todo o conteúdo deste trabalho, exceto quando houver ressalva, é publicado sob a licença Creative Commons Atribição 4.0.

Todo el contenido de esta obra, excepto donde se indique lo contrario, está bajo licencia de la licencia Creative Commons Reconocimento 4.0. 


\title{
Flickr e o rizoma da fotografia em rede
}

\author{
Jane C. S. Maciel
}

Introdução

Nosso interesse em trabalhar com o Flickr neste texto encontra-se no fato de que verificamos sua potência como lócus para se pensar a amplitude e multiplicidade dos usos sociais da fotografia em rede, algo do nosso tempo contemporâneo que ilustra não apenas os modos como a tecnologia fotográfica é apropriada nas múltiplas linhas que compõem seu dispositivo, mas ainda os processos de produção de subjetividade que mesclam, sem confronto, homem e máquina para além da dicotomia moderna natural-artificial. Somos ampliados por essas tecnologias imagéticas que são, em si, conforme afirmara Pierre Lévy (1993), tecnologias de inteligência. Elas mediam nossas relações com o mundo das imagens e da estética de maneira ainda mais intensa, pois não estamos ligados a elas apenas pela recepção, mas agimos constantemente na sua produção, edição, arquivamento e circulação.

É importantíssimo problematizarmos este lócus, que apesar de sua amplitude quantitativa e espacial, ainda é pouco debatido pelas pesquisas sobre a fotografia contemporânea. As imagens, os fotógrafos, as nuances estéticas, as relações parecem camufladas pelo excesso da rede, indiscernível no seu fluxo cotidiano, na velocidade dos seus agenciamentos de enunciação e maquínicos, na heterogeneidade de seus atores (humanos, não-humanos), na multitemporalidade das tecnologias, enfim, na complexidade que é, em si, o ciberespaço, a rede. 
Deste modo, é necessário propor análises que deem conta deste universo adaptando-se a ele, movendo-se com ele, usando suas brechas, escapando por linhas de fuga, enfim, modulando a própria análise pelo pensamento que a rede instiga em nós.

Encontramos no conceito de rizoma, de Gilles Deleuze e Félix Guattari, um eixo teórico possível para tratarmos e problematizarmos as características levantadas acima. Partiremos dele e acrescentaremos à discussão outros estudos que auxiliam na compreensão do conceito de rede, hoje tão em voga nas ciências humanas, sociais e na filosofia. ${ }^{1}$ Pretendemos discutir a visibilidade destes arquivos fotográficos compartilhados no Flickr, enormes bancos imagéticos onde são tornadas visíveis e fazem circular as produções do homem comum que na fotografia anterior às novas mídias encontravam-se isoladas em suas dimensões privadas.

\section{Uma plataforma rizomática}

O Flickr (www.flickr.com) é a maior plataforma de compartilhamento de fotografias da internet (embora existam nele imagens dos mais diversos tipos: gráficas, infográficas, videográficas etc.), com uma amplitude universal que reúne hoje mais de 6 bilhôes de imagens, com membros de toda parte do globo e intençôes as mais diversas, imagens que oscilam entre o amador e o profissional.

Ao contrário dos sites de relacionamentos, nos quais as imagens aparecem em conjunto com outras linguagens em narrativas pessoais que formatam lapsos identitários (tais interfaces não têm como foco a fotografia, sendo, sobretudo, como o próprio termo diz, de caráter relacional), no Flickr a imagem fotográfica, ao invés de ser mera co-

André Parente (2004), em seu texto Enredando o pensamento: redes de transformação e subjetividade, levanta uma série de conceitos que, segundo o autor, podem fundar uma verdadeira "teoria das novas tecnologias como rede de comunicação biopolítica”. Entre os autores citados estão: Foucault, Deleuze, Guattari, Lyotard, Serres, Virilio, Latour, Callon e Lévy. 
adjuvante, parece estar ela própria em evidência. Podemos, por exemplo, ver uma foto no Flickr sem precisarmos (apesar de ser possível) entrar em contato com os dados pessoais do fotógrafo, o que ocorre quando percorremos seus conjuntos coletivos, como os "grupos", "exposições" etc.

Tal site, hoje vinculado à empresa Yahoo, possibilita a hospedagem de imagens na formatação de arquivos pessoais e coletivos (perfis, grupos, sets, álbuns, exposições etc.), viabilizando a circulação e visibilidade das imagens e interação dos usuários (através de comentários em perfis, comunidades, fóruns etc.), na medida em que o site também é uma rede social. O site utiliza a categorização e organização das imagens por tags (etiquetas), o que possibilita um sistema de busca nominativo dentro da própria plataforma (folksonomia).

"Compartilhe sua vida em fotos" é a frase inicial do Flickr. Ela resume sua rede de forma mínima, pelo verbo "compartilhar" (relação, troca, ou, como afirma Maffesoli, a estética como fator de socialização), pela totalidade que o substantivo abstrato "vida" evoca, e, por fim, na indicação da tecnologia de linguagem imagética, a fotografia. A pretensão de dar conta do todo (tão antiga quanto a própria fotografia, com seus ímpetos de catalogar a natureza e culturas) é evocada nesse slogan de abertura, convite para a entrada neste universo. Adentramos, assim, no seu fluxo para refletirmos sobre ele, mas a entrada não era única. Como em uma toca, experimentamos suas possibilidades múltiplas de entrada, saída e permanência.

A toca é um exemplo dado por Deleuze e Guattari (2009, p. 22) de um rizoma animal, "comporta às vezes uma nítida distinção entre linha de fuga como corredor de deslocamento e os estratos de reserva ou habitação". As múltiplas entradas são, segundo os autores, uma das características mais importantes do rizoma e aqui é a primeira a ser citada, pois diz respeito ao acesso, palavra tão recorrente no vocabulário on-line. Como temos acesso aos bilhões de imagens deste site? Essa quantidade que de tão exorbitante torna-se impossível de ser 
visualizada em totalidade, logo intensamente abstrata, é distribuída ao longo de diversas ferramentas, sendo as mais comuns os perfis de usuários (a unidade micro, individual), os grupos (os principais espaços socializantes, de encontro), a ferramenta "exposiçōes" (o universo com pretensão estetizante, uma metáfora com o meio artístico), além de outros modelos de arquivo, como álbuns e sets.

Retomando a ordem traçada pelos autores das características aproximativas do rizoma, seus primeiro e segundo princípios são os de conexão e heterogeneidade:

Qualquer ponto de um rizoma pode ser conectado a qualquer outro e deve sê-lo [...] colocando em jogo regimes de signos diferentes, mas também estatutos de estados de coisas. Os agenciamentos coletivos de enunciação funcionam, com efeito, diretamente nos agenciamentos maquínicos, e não se pode estabelecer um corte radical entre os regimes e signos e seus objetos. (DELEUZE; GUATTARI, 2009, p. 15)

Ora, é certo que tais características não são exclusivas da plataforma analisada por nós, sendo a própria internet precipuamente rizomática. Por conexão, no Flickr compreendemos todo um sistema de links e tags nominativas que formam um emaranhado de relações entre fotografias e fotógrafos. Como exemplo, podemos citar a ferramenta das "exposiçōes", ${ }^{2}$ na qual as fotos e suas miniaturas são links que podem direcionar aos perfis de usuários, além de vários outros hiperlinks. As imagens reunidas pelos usuários em um agrupamento em comum (na maioria das vezes temático) são visualizadas por um observador que se depara com uma narrativa não linear, marcada pela heterogeneidade de linguagens fotográficas as mais diversas, contudo achatadas em um formato comum.

2 Resumidamente, as "exposiçōes" ("galleries"são conjuntos de até 18 imagens reunidas ao redor de um tema, postadas por um usuário que recebe, dentro do vocabulário do site, o título de "curador"). Este "expōe", assim, sua rede de referências visuais dentro do próprio Flickr, recorrendo aos seus perfis favoritos ou à busca em outras ferramentas. 
A heterogeneidade da plataforma também é estabelecida por outros regimes de signos. Apesar de ser um site de fotografias, a linguagem textual aparece de diversas formas, desde os títulos das imagens, os casuais diálogos em comentários e fóruns, os textos do próprio site e das suas extensões (como o blog do Flickr) etc. Encontramos também imagens que vão além dos suportes fotográficos, como imagens infográficas/sintéticas, ou qualquer outra não digital que venha se converter à lógica binária. A relação maquínica que estabelecemos com a materialidade dos suportes por onde acessamos, computadores, celulares e câmeras, e seus modos de visão constituídos pelas telas e visores, também agenciam nossa relação com a imagem.

\section{Explorar}

As fotos mais interessantes do mundo estão aqui mesmo.

O Flickr abriga mais de cinco bilhões de fotos do mundo. Dê uma olhada em outros universos mergulhando na galeria oficial da Casa Branca ou nas mais novas imagens da NASA. Ou explore um periodo da História com as coleçōes de arquivos do Smithsonian, da Biblioteca do Congresso NorteAmericano e muito mais noThe Commons. Veja o mundo pelos olhos de outra pessoa, aqui mesmo
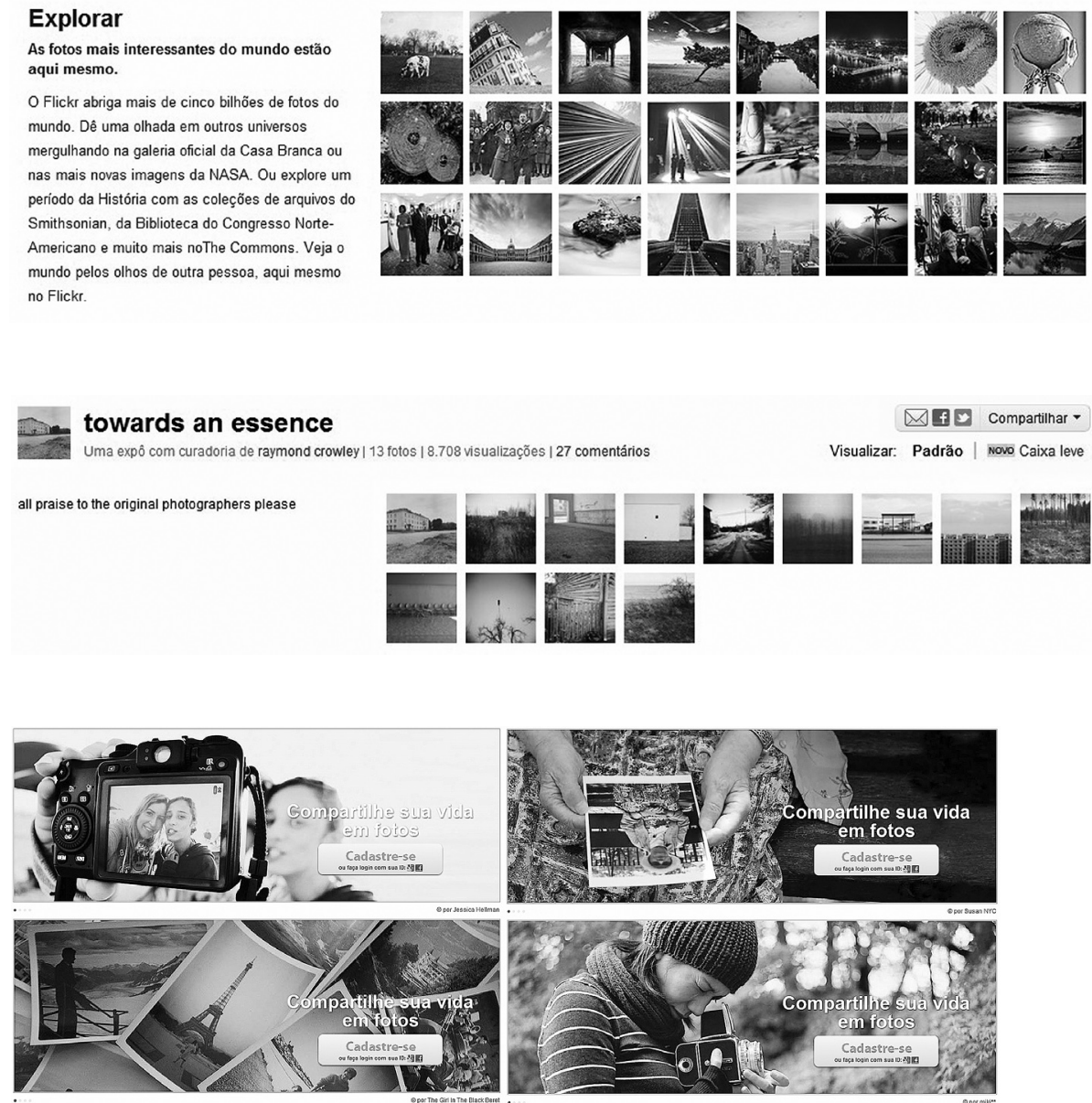

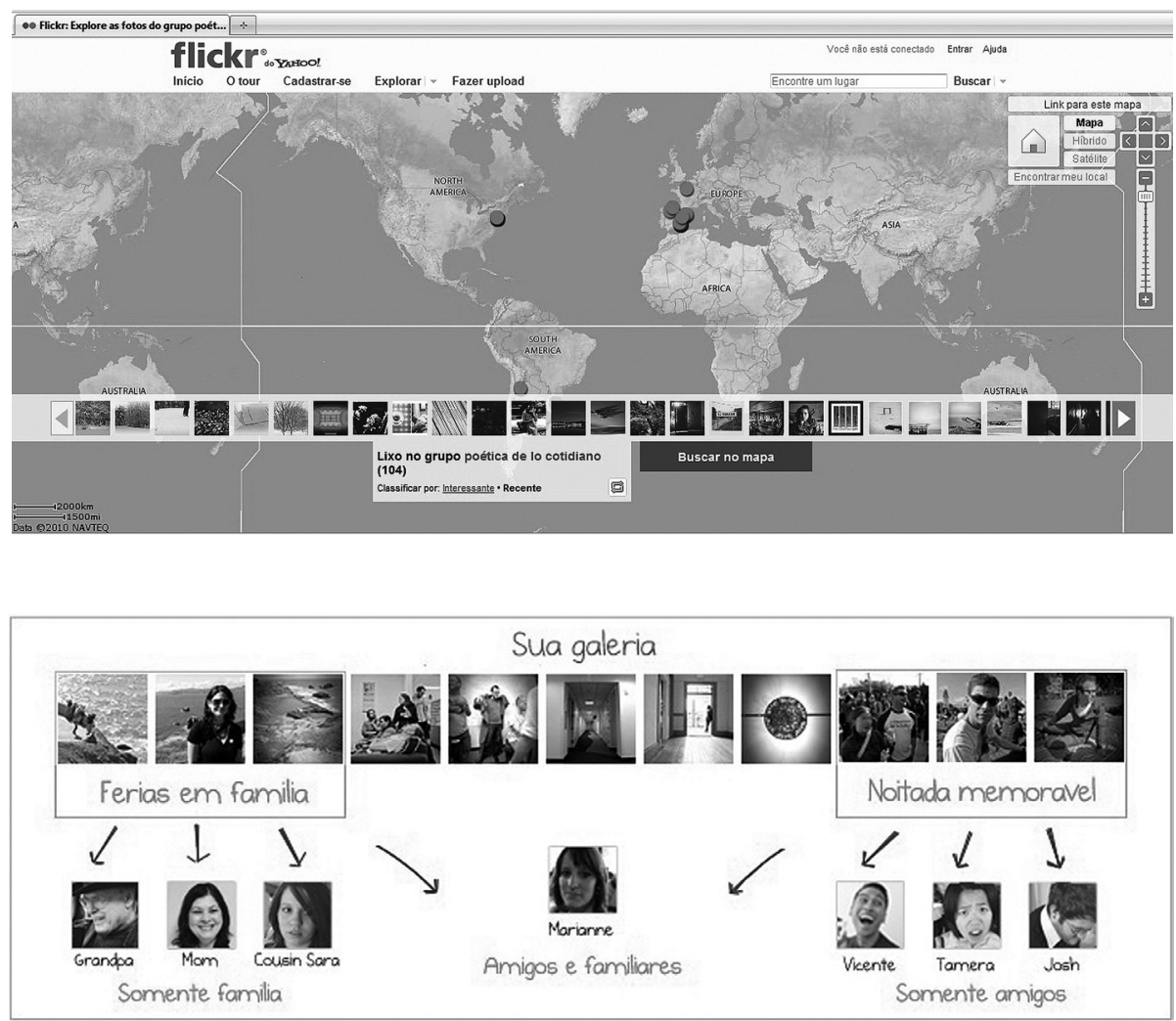

Fonte: Disponível em: <http://www.flickr.com>

As fotografias acima são quatro das doze imagens que se alternam aleatoriamente no layout de abertura do Flickr. Elas são uma seleção discursiva feita pela equipe do site e podem nos ajudar a exemplificar um pouco tal heterogeneidade. Cada uma elucida relações distintas que temos com as máquinas e imagens fotográficas.

$\mathrm{Na}$ primeira, um autorretrato digital que funciona como um espelho cuja imagem é avaliada imediatamente pelo uso do visor. Este gestual tão recorrente em nossos dias, braço alongado permitindo um enquadramento ao acaso, mas remediado pela possibilidade de se deletar o erro e partir para outra tentativa, é registrado pela lente de outro equipamento, uma imagem dentro da outra. Essa interconexão repete-se também na segunda e terceira: a fotografia de uma mulher sentada em um banco, segurando uma imagem sua com roupa 
idêntica à usada, passa-nos uma ideia de sobreposição de um mesmo momento (nem que este seja forjado), uma fotografia feita, impressa (talvez uma polaroid) e observada pela própria modelo que aparece apenas com suas mãos sobre a saia estampada. O acúmulo de fotografias impressas (algo um tanto em desuso) que parecem prezar por uma memória passada transforma-se em um recurso estético metalinguístico na terceira imagem. Já na quarta foto, notamos outro tipo de visualidade que os visores das câmeras de médio formato proporcionam, como uma pequena câmera escura.

Diante dessas diferenças, é impossível falar, por exemplo, somente de fotografia digital dentro do Flickr, já que o analógico também aparece com força, inclusive havendo uma parte específica para este tipo de linguagem convertida enquanto nova mídia, o Flickr analog (www. flickr.com/analog). Analógico e digital são equiparados, podendo gerar quase completa indistinção, pois o primeiro é digitalizado e o segundo pode apropriar-se de uma roupagem estética com simulações de efeitos de revelação em laboratório, entre tantos outros recursos de variabilidade. Com o surgimento do digital, o analógico é ressignificado entre tantas modulaçôes da imagem, linhas que escapam e suscitam novos usos, novos filetes do rizoma. Este panorama converge também para o terceiro princípio do rizoma que é o da multiplicidade, "inexistência, pois, de unidade que sirva de pivô no objeto ou que se divida no sujeito", ou ainda, como acrescentam os autores:

Um agenciamento é precisamente este crescimento das dimensões numa multiplicidade que muda necessariamente de natureza à medida que ela aumenta suas conexões. Não existem pontos ou posiçōes num rizoma como se encontra numa estrutura, numa árvore, numa raiz. Existem somente linhas. (DELEUZE; GUATTARI, 2009, p. 17)

Estas linhas (lembrando também a própria concepção de dispositivo ampliada por Deleuze) caminham tanto em direção a uma territorialização, quanto para uma desterritorialização, como traz o quarto 
princípio de ruptura a-significante. No caso do nosso rizoma, é necessário frisar, neste sentido, que estas linhas são infinitamente móveis, já que o site é frequentemente atualizado em seus recursos lançados e retirados de linha, bem como pelas atualizações dos próprios usuários. Isso faz com que a cartografia do site torne-se cada vez mais complexa e instável, impossível de ser vista ao todo.

Por fim, os quinto e sexto princípios do rizoma são os da cartografia e de decalcomania, "um rizoma não pode ser justificado por nenhum modelo estrutural ou gerativo". Poderíamos então nos questionar se os recursos acima citados não seriam em si estruturantes, o que traria um paradoxo no seio desta discussão. Vejamos: no texto, Deleuze e Guattari levantam neste ponto as críticas aos modelos estruturantes da Linguística e da Psicanálise, compreendendo-as como modelos representativos de uma realidade já feita, a partir de uma árvore que hierarquiza eixos de significância e subjetivação pré-estabelecidos para a língua e para o inconsciente, respectivamente, através de decalques reproduzíveis ao infinito (a exemplo do "decalque estereotipado" do Édipo). Ao contrário dos decalques, aparece a metáfora do mapa. A ideia do mapa para nós é mais pertinente diante da instabilidade que se dá no site, que não é constituído apenas por uma equipe gestora, mas principalmente mantido pela totalidade dos usuários que podem criar, apagar, nomear e descrever agrupamentos, arquivos, imagens, entre tantas outras funções de autogestão (mesmo que essa seja pré-determinada pelas configuraçôes disponíveis).

O mapa é aberto, é conectável em todas as suas dimensões, desmontável, reversível, suscetível de receber modificações constantemente. Ele pode ser rasgado, revertido, adaptar-se a montagens de qualquer natureza, ser preparado por um indivíduo, um grupo, uma formação social. Pode-se desenhá-lo numa parede, concebê-lo como obra de arte, construí-lo como uma ação política ou como uma meditação. (DELEUZE; GUATTARI, 2009, p. 22) 
Toda esta perspectiva dada pelo rizoma busca romper com os dualismos maniqueístas de estruturas que definem, por pontos e posições, sistemas centrados ou mesmo policentrados. Tal conceito auxilia em nossa discussão não apenas porque serve para visualizar o site como um todo, porém, mais ainda, demonstra muito da relação que temos com o ciberespaço, principalmente nessas plataformas colaborativas nas quais os usuários são os formatadores dessas totalidades mutantes. O Flickr é compreendido por nós como uma máquina de imagens, uma extensão e complemento da máquina fotográfica, permitindo a circulação, o arquivo e a socialização dos "observadores-operadores". ${ }^{3}$

Os autores acrescentam que os rizomas não estão isentos de hierarquias, possuem sim aquelas que são próprias ao seu funcionamento a-centrado. A empresa responsável pela plataforma (Yahoo) possui o poder de programação, mas esta é reformatada com frequência para suprir necessidades esboçadas pelos usuários e/ou clientes (já que estes podem aderir à compra de pacotes mais abrangentes do que as possibilidades de uso gratuito, inscrições pagas - Flickr Pro - que permitem ampliar os recursos de postagem). Por outro lado, os próprios usuários podem se colocar também em uma posição ativa, enquanto gestores de comunidades, proponentes de exposições, classificadores etc.

\section{A fotografia em rede}

O Flickr pode ser pensado enquanto uma máquina de imagem que explora em rede as potencialidades dos regimes de visibilidade da fotografia (apesar de, como já dissemos, não se limitar apenas a essa linguagem). Complementar à tecnologia das câmeras fotográficas que são responsáveis pela inscrição nos suportes (analógico ou digital), tal site trabalha com a circulação da imagem para além de qualquer su-

3 Falamos de "observador-operador" como um "personagem conceitual" que seria ao mesmo tempo observador de imagens e operador de tecnologias imagéticas de produção, edição, arquivo e circulação, utilizando-as para expressar sua subjetividade. 
porte, na medida em que é uma plataforma zerodimensional, usando a expressão de Flusser (2008).

Tais imagens não estão mais na bidimensionalidade das superfícies fotossensíveis originais, nem na materialidade das cópias, elas estão convertidas em informações binárias, que devido à sua flexibilidade permite o acúmulo de imagens arquivadas de maneira fluida. Enquanto um artefato técnico, tal tecnologia disponível na rede de alcance mundial - world wide web - permite o arquivo infinito (o infinito enquanto a própria utopia da rede), que hoje tem mais de 6 bilhões de imagens. Não se trata apenas de um local de depósito, mas também um lugar de passagem, de observação no trânsito de fluxos imagéticos contínuos, instáveis e mutantes.

O uso cotidiano de tecnologias em rede em diversas dimensões da vida contemporânea só acentuou a discussão de que nosso próprio pensamento organiza-se também em rede, ou, como afirma ainda Deleuze e Guattari (2009, p. 25), rizomaticamente:

O pensamento não é arborescente e o cérebro não é uma matéria enraizada nem ramificada. $\mathrm{O}$ que se chama equivocadamente de "dendritos" não assegura uma conexão dos neurônios num tecido contínuo. A descontinuidade das células, o papel dos axônios, o funcionamento das sinapses, a existência de microfendas sinápticas, o salto de cada mensagem por cima destas fendas fazem do cérebro uma multiplicidade que, no seu plano de consistência ou em sua articulação, banha todo um sistema, probabilístico incerto, un certain nervous system.

Vale ressaltar que esta concepção orgânica da rede não é nada recente. Em seu texto A filosofia da rede, Pierre Musso (2004) faz um levantamento da gênese deste conceito e de suas metáforas que oscilam, principalmente, entre as redes de tecelagem (do latim retiolus, malhagem têxtil) e o organismo humano. A compreensão do corpo como uma rede vem desde a Antiguidade, com os comentários sobre a circulação sanguínea pela medicina de Hipócrates, a Descartes, que 
emprega o termo "renda" para descrever a superfície do cérebro em Tratado do Homem, além de uma série de concepções médicas desde o século XVII. Esta concepção de rede só foi ampliada na virada para o século XIX, relacionando-se aos ofícios da engenharia de transporte ferroviário e de telegrafia, redes construídas sobre o território.

Esta desmaterialização atinge graus máximos com a tecnologia computacional, de modo que a ciência e a tecnologia contemporâneas correspondem ao desenvolvimento da nossa própria subjetividade e cognição, algo que coincide com a própria noção de dispositivo e dos seus preenchimentos estratégicos que suprem as necessidades humanas em determinados momentos históricos. Em se tratando da nossa relação subjetiva com as imagens fotográficas, o Flickr, enquanto máquina rizomática de imagem, proporciona ao "observador-operador" possibilidades múltiplas de arquivo e a interação em fluxo (com as imagens e com seus produtores), fazendo ver e fazendo falar imagens que podem ir além da simples concepção de informação. Sendo apenas uma das várias plataformas de compartilhamento de imagem em rede, o Flickr é extremamente ilustrativo desta circulação, não apenas por ser a maior, mas pela complexidade que assumiu.

A maneira como circulamos as fotografias tem relação direta com as intenções de produção, os anseios estéticos, os afetos que podem ser gerados etc. Enquanto objetos, as fotos jamais poderiam circular como fazem hoje, "imaterialmente". Tal nível de abstração, próprio das novas mídias, incentiva outras práticas ou atos fotográficos, marcados pela visibilidade que a imagem captada pode assumir, para além de dimensões apenas privadas (no sentido de álbum de família). Em rede, a fotografia, além de múltipla e heterogênea, como citamos, torna-se potencialmente onipresente, podendo ser consumida na medida das conexôes produzidas pelo "observador-operador". 
O ciberespaço e suas redes apresentam-se como espaços heterotópicos, ${ }^{4}$ ou seja, elas sobrepõem vários espaços e se ligam por parcelas de tempos também distintas (heterocronias). O que na cultura moderna mostrava-se nos arquivos gerais dos museus e bibliotecas, nos quais tempos e espaços são acumulados e organizados, agora se mostra reconfigurado às culturas e linguagens do nosso tempo, a exemplo destes arquivos cibernéticos de imagem.

Em nossos dias, o espaço torna-se topológico: passa a ser definido pelas relações de vizinhança entre os pontos e elementos, e forma séries, tramas, grafos, diagramas, redes. [...] É exatamente esse local de acumulação do mesmo enquanto outro que nos leva a dizer, quando estamos na rede, que estamos aqui e lá ao mesmo tempo, e que caracteriza a heterotopia pós-moderna. A heterotopia está longe de ser ameaçada pelo espaço da multimídia e da rede, cuja a lógica é a mesma: co-presença topológica, tramas das redes. (PARENTE, 2004, p. 100)

Citemos neste ponto a ferramenta Commons do Flickr (www.flickr/commons), através da qual são disponibilizados na plataforma acervos fotográficos de diversas instituições públicas, como museus e bibliotecas, sendo os usuários convidados a adicionarem tags e comentários sobre as fotos dos arquivos. ${ }^{5}$ Deste modo, o site vai além

4 A noção de heterotopia ("lugares-outros") aparece na conferência De outros espaços, de Michel Foucault, na qual o autor fala da história do espaço na cultura ocidental, desde o espaço medieval hierarquizado e localizado, rompido no século XVII com o conceito de infinito lançado por Galileu (da localização à extensão), culminando na problemática do sítio, desde a cultura moderna até a contemporânea. O sítio, por sua vez, substitui a extensão de um espaço infinitamente aberto e se fundamenta nas relações de proximidade entre certos pontos e elementos, através da constituição de séries. Neste sentido, Foucault afirma que "a nossa época talvez seja, acima de tudo, a época do espaço. Nós vivemos na época da simultaneidade: nós vivemos na época da justaposição, do próximo e do longínquo, do lado a lado e do disperso."

5 Segundo o site, "programa tem dois objetivos principais: aumentar o acesso a coleções fotográficas de propriedade pública e fornecer um meio para que o público geral contribua com informaçôes e conhecimento". No layout da página de entrada do Commons, encontramos na parte inferior o seguinte comentário: "Qualquer membro do Flickr pode adicionar tags ou comentários a essas coleções. Se você não liga pra isso, é uma vergonha. Isso é para o bem da humanidade, cara!”. 
da pretensão de um arquivo atual, incorporando também arquivos passados, "históricos", que são evocados e equiparados nesta heterocronia complexa.

Para aqueles que não o conhecem, existem várias alternativas oferecidas pelo próprio site em ferramentas como "tour", "descubra", "explorar". Podemos nos perder com segurança navegando em um mar de imagens, tendo a mobilidade expandida na imobilidade de um espaço de conexões. Temos aqui outra forma de observação móvel (diferente daquela do flâneur benjaminiano), com dois movimentos complementares. Estamos tratando de um dispositivo no qual o observador é também (na maioria dos casos) produtor de imagens, contribuindo para o arquivo no qual ele mesmo percorre.

Por um lado, o ideal de desbravamento que vem desde o uso aventureiro do próprio exercício do fotógrafo moderno, descobridor e selecionador de experiências visuais, parece repetido na promessa de um arquivo infinito. Por outro, a interação com as imagens de outros "observadores-operadores" (e entre os próprios sujeitos) inventariadas colaborativamente. Podemos dizer que, enquanto máquina de imagem, o Flickr funciona como uma tecnologia de apropriação do espaço pela fotografia.

Estamos criando uma relação com a imagem própria deste dispositivo fotográfico: vemos cada vez mais fotografias em tela, seja aquelas produzidas por nós próprios, seja em contato com outros fluxos midiáticos atuais ou históricos que foram também compilados e cujo acesso está cada vez mais disponível, como o famoso recurso de busca do Google Imagens. A materialidade da foto impressa, objeto que era ligado a um anseio de preservação de memórias, está de alguma forma em declínio (apesar de que esta função sempre existirá, se atualizando a esses novos regimes). Relações de proximidade e tamanho também são pautadas pelas formas de exibição possíveis, bem como a quantidade de fotos que vemos e o tempo que levamos para adentrar em 
cada uma. Acumuladas nestes arquivos, as fotografias estão a nossa disposição ao passar de uma tecla.

Assim, nossa subjetividade é afetada por novos estatutos de memória que assumimos diante da visibilidade de fotografias experimentadas por intermédio de computadores e rapidamente sobrepostas a outras que sucedem, ao mesmo tempo em que as experiências vividas são também partilhadas em forma de fotografias. A experiência pessoal funde-se com as demais, constituindo um ambiente consumido como fluxo, para além das noções de acontecimento e evento. Fotografamos hoje tendo influência dessa era de excesso de imagens. Encontrando-se no ciberespaço, a fotografia do homem comum expande-se também naquilo que é capaz de mostrar, não apenas em uma relação afetiva com a memória de eventos marcantes, mas na percepção de banalidades diárias. E foi diante desta quantidade exorbitante de fotos produzidas sem cessar que se tornou imprescindível o surgimento de uma tecnologia que fosse um arquivo organizador, transparente e manipulável.

Com nossas relações mnemônicas fotográficas alteradas, pensando em uma relação causal com o passado, tão comum a várias análises da teoria da fotografia, como as de Barthes (isto-foi) e Dubois (índice), entre outras, o presente parece em voga como o tempo do fluxo e da atualização frequente: mais uma vez, um apertar de um botão (atualizar) pode emaranhar ou renovar as peças deste mosaico. Mesmo que sua relação com o passado exista sempre, a fotografia parece não mais necessariamente refém deste tempo para justificar-se e para mostrarse ao ver. Atualizamos não apenas uma narrativa pessoal que interessa a um círculo próximo que decodificará as imagens segundo uma relação afetiva baseada em relacionamentos do mundo tangível (família, amigos), mas também imagens experienciadas de forma rotineira e entendidas simplesmente enquanto signos estéticos.

Nuances de visibilidade vão se apresentando conforme necessidades específicas: de forma completamente aberta (grupos, exposiçôes, 
álbuns etc.), ou parcialmente fechada, através de controles de privacidade flexíveis, como álbuns direcionados a família e amigos, assim designados pelo usuário, ou ainda fotos restritas somente ao usuário; a visibilidade pode acontecer tanto dentro do site quanto para além dele, sendo permitido, por exemplo, fazer um compartilhamento restrito de "fotos privadas" usando a ferramenta "passaporte de convidado", que concede acesso a qualquer pessoa a um álbum específico, mesmo que ela não faça parte da rede.

A customização dos aplicativos de compartilhamento garante aos usuários a apropriação do site para diversos usos: criação de narrativas pessoais direcionadas a amigos e família; práticas estetizantes as mais diversas através da fotografia como "hobby", ou mesmo com algum anseio artístico; usos profissionais tendo o Flickr como um portfólio imagético etc. As imagens, por sua vez, podem ser identificadas, classificadas e circuladas de diferentes maneiras: inclusão de títulos, descrições, tags, locais (que marcarão a foto em mapas, como citamos anteriormente) e pessoas referenciadas, tudo para criar um contexto para cada fotografia. Elas podem ainda ser comentadas, separadas como favoritas em um perfil, relacionadas em uma exposição, sobrepostas em um grupo, organizadas em um álbum. Por fim, esta rede comunica-se com tantas outras, sites como Facebook, Twitter, blogs, sendo possível criar um módulo do Flickr com apresentação de slides em blogs e sites pessoais.

Para concluir, é importante notar como as noções de arquivo e visibilidade complementam-se neste contexto, e que por mais que existam tais ferramentas para um direcionamento classificatório, o rizoma tem constantemente suas conexões rompidas e outras reformuladas; nada é fixo, o mapa está sempre em constante transformação. Para analisar a fotografia em rede, suas estéticas e as subjetividades manifestas por elas, é necessário fugir de noções essencialistas da fotografia, de uma unidade do campo e da linguagem. Ao contrário, a problematização desta produção do homem comum deve ser es- 
tabelecida sempre em conexão com as demais linhas do dispositivo fotográfico em usos profissionais e institucionais e da rede como um todo. A visibilidade destes arquivos rizomáticos pode levantar grandes questões sobre a atual relação do homem com a fotografia e, mais ainda, com a imagem e a estética.

\section{Referências}

DELEUZE, Gilles e GUATTARI, Félix. Mil Platôs: capitalismo e esquizofrenia. São Paulo: Ed. 34, 1995. (v. 1)

DUBOIS, Philippe. O Ato Fotográfico e outros ensaios. Campinas: Papirus, 1993.

FATORELLI, Antonio. Fotografia e viagem. Rio de Janeiro: Relume Dumará. 2003.

FLUSSER, Vilém. O universo das imagens técnicas: elogio da superficialidade. São Paulo: Annablume, 2008.

FOUCAULT, Michel. De outras imagens. Disponível em: <http://www.ufrgs.br/ corpoarteclinica/obra/outros.prn.pdf>.

LÉVY, Pierre. Os três tempos do espírito: A oralidade primária, a escrita e a

64 informática. In: . As tecnologias da Inteligência. Rio de Janeiro: Ed. 34, 1993.

MAFFESOLI, Michel. Aux creux des apparences: pour une éthique de l'esthétique. Paris: Plon, 1990.

MANOVICH, Lev. What is new media. In: . The language of new media.

The MIT London: Press Cambridge, Massachusetts, 2001.

PARENTE, André. Enredando o pensamento: redes de transformação e subjetividade. In: Tramas da rede. Porto Alegre: Sulina, 2004. 